\title{
LA BRECHA EN PERSPECTIVA: TEXTOS, PRETEXTOS, CONTEXTOS
}

\author{
Andrea Kottow \\ Universidad Adolfo Ibáñez \\ Santiago, Chile \\ andrea.kottow@uai.cl \\ Ana Traverso \\ Universidad Austral de Chile \\ Valdivia, Chile \\ anatraverso@uach.cl
}

RESUMEN / ABSTRACT

La consideración de La brecha (1961) de Mercedes Valdivieso como la primera novela feminista latinoamericana es, ciertamente, mérito de la crítica. Pero sabemos que el "dudoso" primer momento en que en una novela se demanda el divorcio, se reivindica el aborto y la libertad económica de la mujer mediante el trabajo femenino, se sostiene sobre una trama compleja de discursos que ya habían sido enunciados antes. Más que discutir la afirmación de la crítica, nos interesa armar la trama genealógica que posibilita leer La brecha como una novela feminista, revisando algunos textos escritos durante la primera mitad del siglo XX en Chile, como Juana Lucero (1902) de Augusto D'Halmar, Los fracasados (1922) de Delie Rouge, María Nadie (1957) de Marta Brunet, entre otros, además de algunos textos contemporáneos y posteriores a la novela de Valdivieso.

Palabras Clave: La brecha, novela feminista, divorcio, aborto, trabajo femenino.

\section{BREAKTHROUGH IN PERSPECTIVE: TEXTS, PRETEXTS, CONTEXTS}

Regarding Mercedes Valdivieso's La Brecha breakthrough (1961) as the first Latin American feminist novel is certainly a valid critique. But we know that the "questionable" first moment in a novel in which a divorce is filed and abortion, and the economic freedom of women through female labor are advocated, is sustained upon a complex weave of discourses that 
had already been articulated previously. More than discussing existing criticism, we are interested in reconstructing the genealogical weave that makes the reading of La brecha as a feminist novel possible, revisiting selected texts written during the first half of the twentieth century in Chile including Augusto D'Halmar's Juana Lucero (1902), Delie Rouge's Los fracasados (1922), and Brunet's María Nadie (1957), among others, in addition to several contemporary texts to Valdivieso's novel.

KEYWORDS: Breakthrough, feminist novel, divorce, abortion, female labor.

Recepción: 3/07/2021

Aprobación: 13/09/2021

\section{A MODO DE INTRODUCCIÓN}

Una de las razones que contribuye, pensamos, a otorgarle a La brecha de Mercedes Valdivieso el lugar destacado de una de las primeras novelas feministas de Latinoamérica, es su particular estilo ${ }^{1}$. Se trata de una novela breve y condensada que, en pocas páginas, desarrolla el devenir de una vida femenina, que se aleja, sin dudarlo mucho, de los moldes provistos para una mujer en el Chile de los años sesenta. La protagonista-narradora relata sin afectación, sin mayor culpa, sin continuos cuestionamientos, sin sentimentalismo ni lirismo los sucesos que marcan su vida: desde que contrae matrimonio hasta que abandona a su marido y emprende una vida sola con su hijo, se introduce en la vida laboral y consigue, finalmente, la anulación de su vínculo marital. No son tanto las temáticas que tejen la trama del texto -descontento en el matrimonio, malestar en y con el embarazo, la realización de un aborto, el deseo de independencia tanto económica como sentimental, la búsqueda de un trabajo remunerado que permita la vida autónoma- las que determinan la visibilidad de La brecha en el canon de la literatura de mujeres. Pues, al revisar la escritura de mujeres o las temáticas que podríamos calificar de feministas en la tradición literaria chilena, nos encontraremos con textos que muy tempranamente -ya desde principios del siglo $\mathrm{XX}$ - giran en torno a estos mismos tópicos.

Lo rupturista de La brecha, entonces, no sería tanto el reconocimiento -casi programático- de los grandes pilares que han sustentado el sistema

1 Una de las escritoras que colaboraron a establecer este privilegiado lugar para la novela de Mercedes Valdivieso es la mexicana Margo Glantz, que destacara el papel de "pionera" en su prólogo a la edición conmemorativa de sus 25 años. 
patriarcal y han marcado la posición subordinada de la mujer en él, sino más bien la forma de ponerlos en juego. Deseos de separación, anulaciones efectivas, e incluso la insistencia en la necesidad de contar con un divorcio legal, los podemos rastrear mucho antes en la literatura. Infelicidad e insatisfacción sexual, pero también la contraparte -la celebración del placer sexual femenino-, asimismo están presentes en varias narrativas publicadas con anterioridad a la novela de Mercedes Valdivieso. El tema del trabajo -la urgencia de encontrar, tener y sostener un trabajo remunerado, por reconocer en él la única forma de conquistar y garantizar la autonomía-, puede, a su vez, ser hallado en numerosas obras previas. Lo que sí pareciera ser bastante único de la novela de Valdivieso es que va tratando estos temas desde una voz que prescinde de toda una carga afectiva que solía acompañar la aparición de estas problemáticas en literaturas que le preceden. Nos encontramos acá con una mujer, que, si bien a ratos duda y cuestiona sus decisiones, sintiendo miedo e inseguridad, en general avanza con resolución por una serie de decisiones difíciles que conllevan costos a todo nivel: sociales, económicos, emocionales. Estos son asumidos con entereza por la protagonista, sin tampoco alzarse como figura heroica. Es, así, ese estilo desprovisto de moralismo, de culpa, de afectación, pero también libre de un tono que se pretenda modélico, lo que convierte a esta novela en un texto que se instaló como un hito indiscutible en la historia de la literatura en Chile y América Latina ${ }^{2}$. Como señala Raquel Olea, probablemente la primera crítica que repara en la escritura de las mujeres que fueron adscritas a la así llamada generación del 50, entendiéndola como un corpus textual, legible desde ciertas problemáticas y estéticas comunes:

Es Mercedes Valdivieso, en su novela La brecha [...] quien señala una torsión al destino de las mujeres. Sin dejar de ingresar al deber ser histórico, la protagonista -anónima representante de una actitud de género- asume otro destino, rompe el habitus, decide elegir aunque lo nuevo sea desconocido y vago, sin importar los efectos ni el desprestigio, la narración produce otros "efectos de femineidad" (Cixous, p. 61) por el emprendimiento de una acción de políticas corporales, como el divorcio, el aborto, una segunda pareja y el

2 Para Marcelo Coddou, la novela opera una ruptura en dos niveles: "por un lado, con el sistema modelizador narrativo, sus normas léxico-semánticas y, por otro, con el sistema modelizador narrativo, del comportamiento de la mujer en sociedad" (43). 
ingreso al mundo del trabajo, entre otras. Estas acciones constituyen disidencias de las morales familiares y de las obediencias patriarcales, que abren un nuevo destino femenino, otro hacerse mujer, inaugurando otra ley y otro deseo (113).

La brecha que produce la novela en el campo de la literatura, más allá de provocarla desde su título y en la vida de su protagonista, se vincula, entonces, con una ruptura no solo en el plano biográfico de una mujer, sino sobre todo en la escritura que da cuenta de él.

Lo que nos proponemos en las siguientes líneas es recorrer La brecha a partir de las problemáticas que la configuran en tanto novela leída como señera para el imaginario feminista. Reconocemos tres hitos fundamentales desde las cuales la narradora-protagonista de la obra traza el relato de su vida, marcando la autonomía con relación a un hombre que la sustente y valide. En primer lugar, el aborto que decide hacerse, tras quedar involuntariamente embarazada por segunda vez de su marido y haber tenido ya un primer embarazo experimentado con distancia y hasta cierta repugnancia. En segundo lugar, la separación de su marido, insistiendo la narradora hasta las páginas finales del texto en que esta no solo sea efectiva, sino que obtenga estatuto legal. Y, en tercer lugar, el reconocimiento de la importancia del trabajo como medio para la independencia económica, que, con gran lucidez, la protagonista afirma en tanto condición sine qua non para poder llevar una vida verdaderamente autónoma. Lo que proponemos en nuestro análisis es tejer relaciones entre La brecha y otras novelas publicadas con anterioridad en el campo literario chileno, para ir viendo semejanzas y diferencias en el tratamiento de los temas identificados. Es decir, quisiéramos dibujar un panorama que le otorgue no un lugar eminente de singularidad a la novela, sino más bien trazar una constelación de obras, donde La brecha se verá en compañía de otros textos en los que reconocemos movimientos parecidos. Movimientos necesarios para atender a obras que, con tonos diversos y acentos diferentes, han aportado a sensibilizar a lectores y lectoras frente a las desigualdades de género, los moldes patriarcales y las múltiples trabas que para muchas mujeres han resultado en lugares y posiciones de subordinación. Y movimientos que, al mismo tiempo, permiten señalar el lugar particular que adopta la novela La brecha dentro del campo literario chileno. 


\section{EN LAS OSCURIDADES DEL VIENTRE}

En una era donde una de las más importantes consignas de los movimientos feministas reza "Aborto libre, seguro y gratuito" merece la pena revisar las formas en que la literatura ha trabajado el tema del aborto. Tratándose de un tópico delicado, muchas veces tabú, asociado no solo a la vergüenza y a la culpa sino, además, según la jurisprudencia chilena actual, derechamente a la ilegalidad, llama la atención lo temprano que ingresa este difícil tema a la literatura en nuestro campo cultural.

Ya en 1902, Augusto D'Halmar denuncia, con sorprendente clarividencia, la desigualdad de clase con relación al tema del aborto ${ }^{3}$. En su novela Juana Lucero -cuyo subtítulo en su primera edición prometía familiarizarnos con Los vicios de Chile, y que se entiende, según el prólogo del propio autor, como un "estudio social"-, la protagonista es forzada a someterse a un aborto. D'Halmar reconoce de forma muy clara que la problemática del aborto no es tan solo un tema que atañe a las mujeres como sexo y/o género, sino uno que se anuda de forma indisoluble a una condición de clase. Esa falta de libertad y de opciones, provenientes de la ausencia o escasez de recursos, son carencias que D'Halmar acusa desde su prólogo para el Chile de los primeros años del XX. De hecho, propone un epígrafe opcional para su novela, destinado a subrayar los amarres que restringen elecciones y decisiones para su protagonista, incluyendo las que atañen el devenir del propio cuerpo: "Carne de esclava". Palabras encarnadas, cuerpo que se hace eco de las condiciones que marcan la vida de Juana Lucero, una biografía que para su autor no solo saca del anonimato a la protagonista de su novela, sino a toda una clase de mujeres que comparten el destino infeliz de Juana, cuya libertad, nuevamente en palabras de D'Halmar, solo se alcanza al morir. No solo se trata así de entender la posición de "esclava", es decir, no ser dueña de sí, en un sentido figurado, sino, y, sobre todo, en su dimensión corporal: el cuerpo de Juana no le pertenece, no es propietaria de su sexualidad ni tampoco de la decisión de su maternidad. Es, literalmente, "carne de esclava", lo que implica que es carne esclavizada, convertida en ajena para el propio sujeto.

\footnotetext{
Rodrigo Cánovas, uno de los primeros críticos chilenos que le dedica un estudio detallado a la novela Juana Lucero, considera que la inclusión del tema del aborto y la aparición del Instituto Ginecológico de Mme. Rigault, que esconde tras su fachada las intervenciones abortivas, es "un gesto inédito en las letras chilenas del 1900" (137).
} 
Recordemos el devenir de la protagonista de esta novela, la historia de la huacha más insigne de la literatura chilena. Juana hereda de su madre Catalina la "culpa" femenina de haber cedido su sexualidad a las promesas de un hombre que luego no las cumple. Un hombre rico, ahora diputado de la República, que no se hace cargo de que ha dejado embarazada a la costurera de la casa y que nunca (re)conocerá a la hija que engendró con ella. Catalina cría sola y con entereza a su amada hija, a quien cariñosamente llama la "Purisimita". Al estar agonizando por una enfermedad que le costará la vida, Catalina intenta contactar al padre de la chica adolescente para pedirle apoyo económico. El diputado Alfredo Ortiz se desentiende, marcando así el comienzo de un camino de padecimiento y paulatina caída para Juana. Es maltratada por su tía Loreto, primer lugar del peregrinaje que la huérfana Juana debe emprender tras perder a su madre, y luego es instalada en la casa de unos conocidos, donde será violada, quedando embarazada, más allá de sufrir la deshonra de la familia, cargando ella con la culpa de los actos brutales ejercidos por otro. Cuando se celebra en la ciudad la conmemoración de la batalla de Yungay y los integrantes de la casa donde Juana vive de allegada/ sirvienta salen a celebrar a la plaza pública, será atacada por don Absalón, el dueño de casa. La violación si bien será advertida por misiá Pepa, esposa de don Absalón, será enterrada bajo un manto de silencio, como también serán ocultados los intentos tanto del patrón de la casa como de su hijo de seguir abusando sexualmente de Juana:

Porque tampoco era caso del otro mundo este del amo y la doméstica, pan cotidiano en toda casa de Santiago, lo que a la postre es legal, pues, ya que las chinas no tienen idea del honor, justo es que sirvan de salvaguardia a los hombres útiles en la sociedad, que no buscarán así, otras entretenciones perjudiciales para su salud (D’Halmar 121).

El narrador denuncia con este tipo de pasajes que se repiten, una y otra vez, en su relato, la hipocresía de la sociedad santiaguina de comienzos del siglo XX, que aplica brutales divisiones tanto de género como de clase, produciendo sujetos totalmente desiguales entre sí. Las mujeres populares ocupan el escalafón más bajo en la escala social, lo que se evidencia, en última instancia, en que no tienen potestad sobre su cuerpo, que es puesto al servicio, incluso por las mujeres de las clases acomodadas, de los apetitos de sus maridos e hijos, en tanto medida higiénica. No será la primera vez que misiá Pepa haga la vista gorda con relación a las consecuencias que dejan las 
acciones de sus hombres en los cuerpos y vidas de las sirvientes. Filomena ya había corrido la misma suerte, sin que se supiera, cuando comenzó a abultársele el vientre, si el embarazo había sido producido por el padre o el hijo de la casa. La novela describe con brutalidad y sin tapujos el aborto al cual se somete la sirviente:

¡Discreta mujer la Filomena! De la noche a la mañana, sin saberse de qué modo ni en qué momento, pues nunca salía sin la ayuda de nadie, ni rastros que la acusaban, recobró su talle de doncella, sirviendo el almuerzo con la puntualidad de siempre, cuando los vecinos habían oído la noche anterior gritos sofocados, y la policía de aseo, deshaciendo un taco en la acequia que pasaba por la casa pero muchas cuadras hacia la Alameda, estrajo, de entre la basura, el cadáver de un parvulito (D’Halmar 126).

Filomena se somete a un aborto casero, claramente sin los recursos que permitirían el cuidado debido para su seguridad y salud. Los gritos sofocados, acallados, son la imagen que denuncia el dolor de la intervención. Y la aparición de un feto encontrado en las cañerías que recorren la ciudad es el símbolo de lo que ocurre subterráneamente en ella. La apariencia finge una armonía social que no se corresponde con lo que verdaderamente sucede, que queda reducido a basura marginada. Las acequias, es decir, los tubos que transportan excrementos, se colman literal y simbólicamente del estiércol que produce una elite amoral.

A Juana, en tanto, le espera otra suerte, si bien igualmente marcada por la imposibilidad de decidir ella sobre su destino, su sexualidad y su maternidad. Abandona la casa de misiá Pepa y se vuelve amante de Velásquez, un joven de la clase alta que la instala en un departamento que funciona como nido de amor para esta relación oculta. Sin embargo, cuando Velásquez se entera del estado de Juana, decide deshacerse de ella y la entrega al burdel regentado por Madame Adalguise. Solo de a poco y con el transcurso de los días, Juana se dará cuenta en qué tipo de establecimiento se encuentra e, ingenua como es, alberga la esperanza de poder tener a su hijo y redimir sus culpas a través de él. Llega incluso a tejer una gorrita con bullones de gasa y lacitos de mariposas para el innato hijo: “iCon qué ternura pensó en aquel hijo!” (D’Halmar 211). Pero el destino resulta inevitable y un día es llevada por Adalguise a realizarse el aborto, en el "Instituto Ginecológico, pensionado a cargo de Mme. Letizia Schulze de Rigault, Doctora en obstetricia, Diplomada 
en las Facultades de Berlín y París" (D’Halmar 242), como reza con cierta pompa el letrero que pende sobre la entrada de la clínica:

Ya estaba todo arreglado y siguieron conversando las dos mujeres, cuyos oficios guardaban tanta relación. La una, extrangera, (Impunidad y preferencia), hacía medrar la clínica, tras del biombo chino con que, sus clientes, las aristócratas ocultan sus crímenes y aún sus sangrientos castigos. La otra, amparada por las leyes confiaba en la forzosa protección de los hombres para la prosperidad del prostíbulo, y ambas, la doctora y la alcahueta, convergían amistosamente en su fin común de explotar a la misma sociedad depravada. El laboratorio de Mme Rigault prepararía las esposas del porvenir; el jimnasio de Adalguise educaba los futuros maridos. No era nimia, pues, la importancia de esas dos mujeres que tenían en sus manos caprichosas nada menos que la suerte de la especie venidera, pudiendo torcerla a su antojo (ibid.).

La novela de D'Halmar evidencia una trenza que asegura el aborto seguro para las mujeres de la elite, que cuentan con una clínica en la que pueden someterse a una operación supervisada médicamente, por un lado, y que les permite, por otro lado, a los hombres de la clase alta tener sexo con mujeres cuyos embarazos, a su vez, pueden ser interrumpidos en el mismo lugar, intervención pagada por la dueña del prostíbulo. Dos mujeres que así se vuelven no solo serviciales sino que se aprovechan de un sistema patriarcal de clases, donde las mujeres pobres no son dueñas de sus cuerpos: ni para decidir con quién y cuándo tener relaciones sexuales, ni tampoco para deliberar acerca de con quién y cuándo tener o no un hijo.

Lo que D'Halmar denuncia a través de su narrador y con la historia de Juana Lucero es que el aborto es uno de los muchos mecanismos que la sociedad de principios del siglo tiene para asegurar a la elite el lugar de privilegio con el que cuenta y la total subyugación del pueblo a sus determinaciones. Hay un sistema instalado, que pasa por el cuerpo de la mujer, por su sexualidad y por su maternidad, que sostiene la desigualdad no solo de género sino también de clase.

Tanto Filomena como Juana Lucero son retratadas como víctimas de una red de relaciones de poder, donde ellas son forzadas por las circunstancias a someterse a un aborto. Sin embargo, y es este el punto en el que nos gustaría insistir, esta falta de libertad ya estaba instalada de antes en sus vidas: no pudieron, tampoco, tomar, previamente, una resolución sobre su sexualidad. 
El cuerpo se muestra como un lugar de disputa, en el cual se evidencian diferencias de género y de clase. Si bien el tono del narrador pareciera considerar el aborto como un crimen y una matanza, se compadece de las mujeres que deben someterse a uno, y no las culpabiliza a ellas de tal falta a la moral. Esta última marca un sistema vicioso, un Chile que no permite que las mujeres de extracto social popular sean dueñas de sus cuerpos. Las mujeres son víctimas, objetos más que sujetos, sin capacidad de tomar decisiones. Sus cuerpos se ven atravesados por fuerzas que las despojan de la facultad de encarnar ellas su propia corporalidad ${ }^{4}$.

La paulatina sustitución y sustracción del nombre propio de Juana, que pasa de la denominación materna "Purisimita", a ser Juana, adoptando finalmente en el prostíbulo el nombre de la cocotte homenajeada por Émile Zola en su novela Nana (1880), marca a su vez la imposibilidad de la protagonista de ser dueña de sí. La pérdida del nombre va de la mano con el despojo de su cuerpo - maltratado, violado, vendido, intervenido para mantener su valor de mercado-, caída que se sella con la locura de Juana Lucero, que deja de reconocerse como viva y se piensa como muerta 5 .

En la novela María Nadie de Marta Brunet, publicada en el año 1957, nuevamente nos enfrentamos a la historia de un destino de mujer marcado por la desgracia y la imposibilidad de huir de una trama vital que se inscribe en el cuerpo femenino. También en este texto se insiste en una cifra tejida en torno al nombre de la protagonista, recogida en su título. María Nadie es en realidad María López, nombre de mujer común que hace extensible su

\footnotetext{
En su análisis de la novela, Claudia Darrigrandi hace alusión a esta victimización del personaje de parte del narrador, que se trenza con la pregunta por quién controla el cuerpo de la mujer y qué implica esta visión sobre la corporalidad femenina: "Juana, de esta forma, representa las problemáticas representacionales de la figura de la prostituta. Por un lado, es la víctima inocente que es doblegada por la hegemonía masculina (en particular en la escena de la violación), de este modo se opera un control sobre un cuerpo femenino que se lee como amenaza, como peligroso objeto de seducción. Por otro lado, la posibilidad de ejercer un poder, en este caso sexual, sobre el otro "masculino", no es explicitada en las escenas de la novela" (s/p).

Rodrigo Cánovas, en su lúcido estudio de la novela, incluido en su libro sobre la alegoría del prostíbulo en la literatura latinoamericana, marca el devenir de Juana Lucero como un proceso de paulatina desaparición o borradura. Lee la novela, pensándola como el revés del romance nacional, tal como lo planteara Doris Sommer en las Ficciones fundacionales: "en vez de insertarse en la serie central del hogar nacional como hija, sobrina, novia, esposa y madre, Juana ilumina la serie excluida en calidad de guacha, sirviente, costurera, querida y prostituta, hasta borrarse como loca" (133).
} 
experiencia a cualquier otra biografía femenina en el Chile de la década del 50. El "López", apellido que no logra diferenciar a esta María -nombre que aquí adquiere un carácter casi genérico para lo femenino- de otras Marías, será sustituido en la experiencia de la protagonista por "Nadie", es decir una borradura del nombre propio. También en esta novela, como en Juana Lucero, los juegos que se efectúan con y sobre el nombre de la figura literaria son decisivos para las vivencias de la mujer que lo encarna. El texto de Brunet está organizado en dos tiempos. La primera parte de la novela corresponde al intento de María López de rehacer su vida y deshacerse del pasado que, no obstante, la alcanza y condena. En la segunda parte de la novela asistimos al relato que la propia María López hace de su historia de vida, que incluye una desilusión amorosa, un embarazo y el sometimiento a un aborto forzado. En la primera parte de la narración se nos cuenta la vida de un pueblo pequeño, al cual María llega como telefonista a la oficina de correos. Su belleza, su pelo rubio y su talante esbelto la destacan entre las fisionomías más toscas a los cuales los pueblerinos están acostumbrados, valiéndole la envidia y los celos de las mujeres, la admiración de los hombres y la amistad de dos niños pequeños, que creen ver en María Nadie la personificación de un hada salida de sus cuentos infantiles. El conflicto se articula justamente en torno a estos dos chicos, que idolatran a la joven mujer, con la cual juegan en los parajes rurales del pueblo. El Cacho, hijo de Reinaldo y Ernestina, es un niño robusto y fuerte, cuyo mejor amigo es el enfermizo y debilucho Conejo, hijo de Lindor y la Petaca. Los dos matrimonios han visto menguada la armonía familiar por la ruda vida del pueblo, el exceso de trabajo, la monotonía y la estrechez de una cotidianidad sin mayores distracciones. Lindor se escuda en el alcohol y en el burdel, y Reinaldo en un amor de tintes platónicos que le profesa desde su llegada a la telefonista, María López. Un día, el Cacho cree reconocer en la solapa de su padre un ramo de violetas silvestres que el Conejo le había obsequiado a la "niña de los cabellos de oro" (52). Al compartir sus sospechas con el amigo, este cae en un estado de gran tristeza y termina enfermándose gravemente. Dado el frágil estado de salud del niño, Petaca se deshace en preocupaciones por su hijo. Una representación teatral que se dará en el pueblo brinda una luz de esperanza para sus habitantes, prometiendo distracción. Todo el pueblo se reúne y es la primera vez en mucho tiempo que María se topa con sus pequeños amigos. El encuentro tendrá un resultado catastrófico para la protagonista, pues el despechado Conejo intenta evitar el encuentro con el hada que le ha roto el corazón y, cuando María Nadie lo saluda con alegría, la madre, Petaca, explota: "No le basta manosear a 
todos los hombres para también agarrársela con los niños..." (Brunet, María 79). Otras voces de desconfianza frente a la hermosa forastera se hacen oír, y María López -"Mala pájara, María Nadie, al fin. Habría que echarla del pueblo. Fuera..." (79)-, termina arrancándose de los gritos y acusaciones.

La segunda parte de la novela, titulada "la mujer", antecede cronológicamente a este relato situado en el pueblo y nos relata el pasado de María López y, particularmente, las circunstancias que la llevaron a buscar refugio y la posibilidad de una nueva vida en la lejanía de los parajes rurales. Atravesada por el deseo de forjarse su propio camino vital, María López había asumido un trabajo de telefonista en la ciudad en la que vivía, se había independizado de sus padres y habitaba sola un departamento. Con toda su autonomía, a María López la embarga la soledad y el anhelo de un amor. Una noche es invitada a una fiesta y conoce a un hombre alto y bello. El encuentro termina en el departamento de María López y el trato que Gabriel le da a la mañana siguiente es premonitorio de lo que vendrá: "Mírenla a la pollita, igual a la de la canción... [...] Váyase al baño: no sea cochina" (Brunet, María 100). Una vez más, el lector asiste a la pérdida del nombre propio. Ella nunca será María para Gabriel, sino que adoptará una serie de sobrenombres -"pollita", "princesa", "chiquita", "gatita"-, que más que articular un discurso amoroso propio de amantes, borran su nombre y la convierten en (una) cualquiera. María López se vuelve la querida secreta de este hombre rico, que nunca tiene intenciones de formalizar sus relaciones. Ella cae presa de su enamoramiento y pasión, convirtiéndose en una mujer sin voluntad para terminar la relación o cambiarle el rumbo. Y ocurre lo inevitable: María López queda embarazada. A pesar de sus férreos deseos de tener a su hijo ("-Quiero mi hijo y nadie me obligará a que lo pierda" (Brunet, María 107)), es violentamente obligada por Gabriel a interrumpir el embarazo. Él termina por leer el anhelo de tener un hijo como un encarcelamiento al cual ella lo quiere someter:

Lo que quieres es amarrarme a mí. Eso es lo que quieres, ¿entiendes? Pero a mí nadie me amarra a la fuerza. Ni tú ni un hijo. No quiero amarras. ¿Entiendes? No quiero amarras. Ninguna. Y menos que nadie de ti. Anda. Vístete. Voy a llamar por teléfono a mi amigo y a las ocho te vengo a buscar (Brunet, María 107).

En un último intento de escabullirse de su destino, ella sale y deambula hasta el amanecer por las calles. Cuando vuelve a la madrugada: "me agarró violentamente, puso su gran mano sobre mi plexo, me volcó a la cama, y, 
con el mismo automatismo con que había andado cuadras de cuadras, una vez más fui su mujer" (Brunet, María 108).

Lo que sigue puede prestarse para diversas interpretaciones. El texto narra:

Cuando se hubo ido, me desangré en una hemorragia. Tuve tal miedo de morir sin volver a verlo, que por primera vez lo llamé por teléfono. Vino. Trajo a su amigo médico. Me llevaron quemada por la fiebre a una clínica. Me hicieron un raspaje. Pasé allí días solitarios en una pequeña habitación sobre un jardín, sin ruidos, rodeada de una solicitud aséptica (ibid.).

La entrega, una vez más, a una relación sexual con el hombre que le ha dicho clara y directamente que ella es tan solo su juguete sexual, que no tiene intenciones serias con ella y que además hará todo lo posible para forzarla a abortar, puede implicar simbólicamente una renuncia de María Nadie no solo a los deseos de tener a su hijo, sino también a reclamar la posesión de su cuerpo. La hemorragia no sería así sino una consecuencia de un reconocimiento, por parte de la mujer, de que ella no es dueña de su cuerpo. Gabriel ha convertido a María en su "pollita", "chiquita", "princesa", borrando no solo su nombre propio sino también su corporalidad. Ni su sexualidad ni su potencial maternidad le pertenecen; la tachadura de su nombre, la conversión de María López en María Nadie, marca la borradura de la mujer. Paradójicamente, es ahí donde surge para la protagonista la posibilidad de volver a ser ella, para lo cual se aleja de Gabriel y busca una vida en paz y soledad en el pueblo. No obstante, su historia se ha inscrito en su cuerpo y volverá a salir a la superficie, marcada en la expulsión del pueblo.

Hay una serie de semejanzas en las historias narradas por Marta Brunet y por Augusto D'Halmar. En ambas prima la imagen de un sistema social donde la mujer no tiene libertad para adueñarse de su propio destino y en los dos casos este último está indisolublemente vinculado al cuerpo, a la sexualidad y la reproducción. Las mujeres, que terminan borradas en sus nombres y en sus vidas, no deciden sobre sus cuerpos, que se vuelven un lugar de disputa en el que se impone la supremacía masculina. Convertidas en víctimas de un patriarcado brutal, Juana Lucero y María Nadie acusan, desde las páginas que habitan, la violencia de género que las tacha hasta hacerlas desaparecer.

Como hemos apuntado más arriba, también en la novela La brecha se produce una borradura del nombre propio. Pero el gesto adopta desde los 
inicios del texto otro talante. Acá la falta de nombre propio no convierte a la mujer en una víctima que ha perdido incluso lo primero que se recibe al nacer -el nombre-, sino que vuelve la historia de su narradora en una que podría ser protagonizada por cualquier mujer. Una especie de epígrafe declara la intención del texto: "El personaje de esta novela no tiene nombre, pero podría ser el de cualquier mujer de nuestra generación" (Valdivieso, La brecha 8). Desde pequeña, la protagonista reconoce el trato desigual que se les da a niños y niñas, y envidia las libertades de su hermano, que lleva el nombre Andrés, cuya etimología griega refiere a la virilidad y la valentía. La vida del niño se vuelca hacia afuera, mientras ella es instada a permanecer en casa, donde está siempre bajo la mirada de su madre, preocupada de hacer de su hija una mujer que siga los patrones de género hegemónicos: debe casarse y tener hijos, y asegurar de este modo el funcionamiento del entramado social. Se casa sin particular enamoramiento, pero tampoco siente aversión hacia Gastón, con el cual conoce el placer sexual: "Partí virgen. Contrariamente a los cuchicheos de la hora del recreo en el colegio o después en el salón, no tuve molestias. Tras un ligero dolor, un atisbo de placer, el primero, in crescendo" (Valdivieso, La brecha 18). Sin embargo, aparece un elemento que le mengua el disfrute del sexo y es la demanda de posesión: "En la escala ascendente del placer resonó como una nota en falso aquella frase que mi marido repetiría durante años, gimiente y triunfal: -¡Mía! ¡Eres mía!” (ibid.). Así, también en la novela de Valdivieso aparece el cuerpo femenino como un campo de batalla, uno en el que se juega la pregunta por quién es, finalmente, su dueño. La sexualidad se convierte en una escena de lucha, pues la posesión sexual parece implicar la toma de una serie de decisiones que atañen el cómo se viste y se acicala el cuerpo, cómo y hacia dónde se moviliza, con qué otros cuerpos se relaciona y de qué modo, cuándo y cuánto sexo tiene ese cuerpo, y cuándo y cuántas veces se reproduce. Es por ello que la narradora repara en estas expresiones de posesión, despojándolas de todo potencial romántico o erótico. Es esta misma sensación de una continua pérdida de libertades la que la embarga cuando le diagnostican su embarazo: "Todo pasó rápido. Preguntas van, respuestas se dan. Como en sueños oí que esperaba un hijo. No podía ser, si jamás lo había pensado. Esas cosas le sucedían al resto, ¿pero yo qué haría? ¿Y mi libertad?” (Valdivieso, La brecha 23). En ningún momento el embarazo se describe como un momento feliz; la protagonista vive su cuerpo como una cárcel y la perspectiva de tener un hijo no le brinda sentimientos de completitud ni alegría. Su evidente estado de melancolía produce un mayor distanciamiento con Gastón, que se desespera con esta 
mujer que se resiste a adoptar las actitudes de una esposa y madre "normal": "El precioso juguete se había echado a perder" (Valdivieso, La brecha 31).

Si bien el embarazo es vivido sin ningún atisbo de felicidad ni expectación, una vez que el niño nace, la narradora siente ternura por su hijo. A pesar de ello, se promete que no habrá más embarazos ni hijos: “Apreté las manos contra mi vientre sobre las sábanas: 'Nunca más. Haré lo necesario para impedir que esto se vuelva a repetir. Nunca más"' (Valdivieso, La brecha 34). Y así transcurre el tiempo: "Sucesión de días, meses, años" (Valdivieso, La brecha 37). Las desavenencias en el matrimonio se hacen cada vez más evidentes. Madre e hijo forman una alianza contra el padre, que siente que se le escabulle lo que en realidad le pertenece. La protagonista evade como puede un nuevo embarazo y la escena familiar se vuelve paulatinamente más violenta. Gastón cree que le ha faltado el ejercicio de una autoridad más firme: "-Y creo que es falta de firmeza contigo. Voy a tenerla. Debes pensar que al menos quien paga y mantiene tus gastos soy yo; aunque sea sólo por eso me respetarás" (Valdivieso, La brecha 41-42). Pero la protagonista ya ha emprendido un viaje de alejamiento de su marido y este no logra recuperarla, ni siquiera a partir de este gesto inútil en pos de reclamar un poder que ella siempre supo burlar. Ella conoce a un hombre del cual se enamora y tiene un intenso amorío con él. Frente a la infelicidad que reina en el matrimonio, ella incluso llega a proponerle a Gastón que se separen, lo que es rechazado de forma categórica por él: “¿Supones que yo aceptaré haber fracasado en mi matrimonio? Seguiremos juntos aunque sea necesario darte de bofetadas" (Valdivieso, La brecha 54). Y así, en algún momento, ocurre lo inevitable, y la protagonista vuelve a quedar embarazada. La novela es llamativamente escueta para relatar la decisión que toma de abortar, sin dudarlo en ningún instante: 'Con el resultado 'positivo' de los exámenes, consulté a Marta; esta, a alguien, y por fin tuve dirección de un médico "especialista"" (Valdivieso, La brecha 64). Esta escena contrasta fuertemente con los relatos de los abortos revisados en D'Halmar y Brunet. Acá es la mujer la que la toma la decisión libremente; no es forzada por nadie a someterse a esta intervención. Es más, es evidentemente algo que debe hacer en contra de las voluntades y al margen del conocimiento de quienes la rodean-Gastón, su madre y su suegra-, e impone acá el derecho de ella a decidir sobre su cuerpo y su maternidad. No obstante estar muy segura de no querer tener más hijos, el aborto es descrito como un paso que implica miedo, fantasmas y dudas morales: 
En el cielo blanco de la pieza, la luz de la lámpara que venía del piso reflejaba un monstruo negro que se movía con lentitud. El dolor era la lucha de la especie por sobrevivir y lloraba por mis ojos. Quebrantaba yo en esos momentos todos los cánones, las normas; me convertía en una réproba que merecía castigo; el horror transpiraba en mi frente en mis manos, en mi cuerpo; corría, mojaba mis cabellos, llegaba hasta la camilla (Valdivieso, La brecha 68).

La narradora explicita su dolor y el aborto, si bien aparece como la única solución posible para ella, no es una experiencia fácil. El episodio cierra con una escena que la recrea a ella abandonando la clínica en compañía de su amiga Marta, llorando en el auto. Posteriormente, nunca volverá a referirse a su aborto.

$\mathrm{Si}$, siguiendo a Silvia Federici, la dominación de las mujeres ha pasado históricamente por la regulación de la producción a través de la reproducción, es central pensar el aborto desde la pregunta que nos sugieren los textos literarios revisados: ¿quién y por qué razones decide el aborto? Federici propone, en su ya clásico texto Calibán y la bruja (1998), una revisión de la noción marxista de la acumulación primitiva desde una perspectiva feminista, lo que implica entender que la división sexual del trabajo somete las labores femeninas y la función reproductiva de las mujeres a la fuerza de la producción. La primera consecuencia de este planteamiento es que el género emerge como una categoría que solo cobra su pleno sentido entendida en tanto especificación de las relaciones de clase. Es decir, el control de la reproducción que ejerce el dominio patriarcal sobre el cuerpo de las mujeres está entretejido de forma indisoluble a la clase social, o sea, a la economía.

En la novela de D'Halmar, Juana es forzada al aborto por dos movimientos de índole económica: por un lado, por la dueña del prostíbulo, Adalguise, que está asegurando su fuerza de trabajo, basada en el cuerpo sexualizado de Juana; y, por el otro lado, por parte de los posibles padres del potencial hijo, que evitan la producción de bastardos o huachos, que no tienen lugar en el sistema social y económico. El aborto es decidido, entonces, por parte de quienes aseguran el funcionamiento de un sistema capitalista patriarcal. En la narración de la historia de María Nadie, se nos presenta un escenario parecido. Gabriel fuerza a María a abortar, porque evita de este modo un hijo ilegítimo que es una carga económica en un sistema que no le asigna ningún lugar. María, que debe trabajar para sostenerse económicamente, no debe peligrar lo que le permite ser rentable laboralmente, es decir, su cuerpo. 
En el caso de La brecha, opera asimismo una componente de clase indudable. No es casual que el capítulo siguiente al que relata el aborto comienza planteando el dilema económico de la protagonista. Habiendo decidido separarse y habiendo ejercido ella la decisión sobre el devenir de su cuerpo y su maternidad, lo que resta para alcanzar la independencia deseada es la autonomía económica. Es, por lo demás, la clase social privilegiada la que le permite a la narradora de la novela de Valdivieso concebir las posibilidades de una vida que se aleja de los cánones hegemónicos de género de su época.

$\mathrm{Al}$ reconocer este enlazamiento entre género y clase, Federici insiste en que "las actividades asociadas a la 'reproducción' siguen siendo un terreno de lucha fundamental para las mujeres" (27). Sexualidad, embarazo y maternidad son, en los textos revisados, puntos álgidos para pensar el sistema patriarcal $\mathrm{y}$ el control que ejerce sobre el destino de las mujeres. Y es decisivo que, vista en la constelación que hemos propuesto, La brecha posibilita pensar el aborto en tanto producto de la voluntad de la mujer y no como el ejercicio de un poder masculino, abriendo así también la opción de considerarlo desde la liberación y no desde una posición victimizada. El cuerpo se presenta, al plantearse la problemática del aborto, como un terreno álgido de lucha, donde se disputan el poder y la subordinación pues, como propone Federici, "en la sociedad capitalista, el cuerpo es para las mujeres lo que la fábrica es para los trabajadores asalariados varones: el principal terreno de su explotación y resistencia" (29-30).

\section{¿HASTA QUE LA MUERTE NOS SEPARE?}

El divorcio también fue una temprana demanda de las luchas feministas. Comienza a visibilizarse con fuerza durante las primeras décadas del siglo en todo el cono sur, si bien en Chile recién comienza a discutirse seriamente a partir de 1924. Es por ello que sorprende la prematura preocupación de Delia Rojas -quien firmaba sus libros con un afrancesado "Delie Rouge"por el tema, primero en Mis observaciones, de 1915, y años más tarde en su novela Los fracasados, de 1922, escrita con un expreso motivo político: "únicamente persigo un fin social, y me valgo de la forma novela para hacer aceptables las ideas que por sí solas son muy áridas” (5).

La novela, tal como se lo propone su autora, tiene la forma de lo que llama un "Manual de controversia", donde expone una serie de argumentos a favor del divorcio en voz de sus tres personajes centrales. Señala que escribe "para 
las mujeres de mi país" (ibid.) y, en particular, para aquellas que "habéis deseado más de una vez, oír una voz que clame justicia para vosotras" (Rouge, Los fracasados 7). Las motivaciones para aprobar el divorcio benefician a ambos sexos, incluidos los hijos -según lo relatan sus personajes-y, sobre todo, permitiría ahorrarse una serie de consecuencias nefastas que afectarían sobre todo a la moral de las mujeres en la lucha por la subsistencia.

Pero antes de exponer sus argumentos, la novela presenta la situación amorosa de sus casos ficticios. Elena, una hermosa mujer que posee todas las cualidades físicas y morales que la acercan a las protagonistas modélicas del siglo XIX -belleza aria, juventud, bondad maternal y pasión-acarrea un historial trágico en materia sentimental. A pesar del intenso y correspondido amor entre ella y su marido Julio, este, por presumir frente a sus amigos de farra, la habría engañado con una cualquiera contrayendo una enfermedad venérea muy larga y dolorosa, cuyo padecimiento decide finalizarlo con el suicidio. La lozanía de su desdichada mujer la salva de contagiarse; no así al hijo menor del sifilítico, quien nacería poco después de la muerte de su padre con serios problemas de salud. Una situación económica holgada le permite a la viuda vivir en un hotel, pensando solo en el cuidado de sus hijos y descartando de su mente la posibilidad de comenzar un nuevo romance por temor a repetir los mismos infortunios anteriores. Gastón, en cambio, no deja de pensar en su vecina Elena. Vive en su mismo hotel, frente a su habitación, y admira su hermosa piel alabastrina, su erguido pecho y la dedicación que brinda a sus dos pequeños. Como ella, acarrea desilusiones en materia amorosa. Cuando aún era estudiante, habría experimentado el fuego del amor con una mujer diez años mayor que él. La que fuera originalmente su ardorosa amante, termina convirtiéndose en su legítima esposa, para con el tiempo llegar a ser una "vieja de cuarenta y cinco, incapaz de inspirarle una pasión" (Rouge, Los fracasados 22). Vieja, celosa y sin siquiera brindarle la dicha de ser padre, Edelmira será para Gastón un estorbo en su juvenil anhelo de felicidad. En cambio, el fino empeine de Elena, el nacimiento de la pierna torneada, las caderas muy bien formadas, los labios tan rojos, su cuerpo, su rostro, piensa Gastón, conforman "un tipo de belleza excitante" que pareciera haber "sido hecha exprofeso para el amor" (Rouge, Los fracasados 42), despertando sus "ansias de vivir, de que esa mujer fuese suya, de verse revivir en un hijo de ella" (Rouge, Los fracasados 24).

La tercera "fracasada", Margarita, es una encantadora, aunque decepcionada joven de 27 años que sigue atentamente la polémica sobre la legislación del divorcio, a través de una amiga escritora. El tema le toca directamente, 
tal como al resto de los personajes, pero su situación, si es que es posible comparar, la tiene particularmente frustrada y no ve más salida que un cambio legislativo. Casada a los 16 años con un primo por un arreglo matrimonial que definieron los padres de la pareja, soporta los primeros años una muy difícil convivencia hasta terminar habituándose e, incluso, llegar a sentir cierto afecto por el marido. Pero la aparición de una prima lejana de Margot, que se instala a vivir con ellos, le arrebatará el marido, su estabilidad y la posibilidad de realizarse como madre. Por dignidad, Margot abandona el hogar conyugal y vuelve a la casa materna, sin olvidar que el tiempo transcurre y muy pronto le quitará definitivamente la oportunidad de tener un hijo.

Estos tres personajes saben que la opción de establecer una nueva relación de pareja y realizarse a través de la maternidad o paternidad, a pesar de su juventud, está vedada para ellos. Se llaman "fracasados" y descartan la idea de enamorarse nuevamente, en contra de los deseos de sus cuerpos aún bellos y apasionados. Así, tan solo bastará con la persistencia de Gastón para que Elena termine rindiéndose al irrefrenable amor, que desatará la predecible catástrofe en sus vidas y, sobre todo, la evidente urgencia de legislar a favor del divorcio. La novela, entonces, ilustra el problema con estos tres casos y además refuerza la argumentación con una interesante conversación entre ellos -que ocupa buena parte del texto-, donde se debaten las ideas divorcistas. El "manual de controversia" al que se refiere la autora en el epígrafe -y que incluye notas al pie de página con referencias bibliográficas, datos y cifras de actualidad-, así como el valor de las pensiones que reciben las madres por ley, son, a la vez, alusiones a los principales polemistas de la discusión y comentarios sardónicos hacia los críticos literarios y la disposición "contra viento y marea" de la escritora por continuar en la ardua tarea de defender sus ideas a pesar del juicio de los críticos. Además de la documentación especializada que da espesor a la discusión, la autora hace su acto de presencia en notas al pie - que aluden a sus novelas y a los apuntes de sus clases de Derecho en la Universidad de Chile- y en el personaje de una anónima escritora-divorcista, para algunos, anarquista, para otros-, que sustenta la argumentación de su amiga y admiradora Margarita y que Gastón complementa informadamente, demostrando que no se trata de un asunto de exclusiva preocupación de las mujeres.

El razonamiento es más o menos el siguiente: frente a la "natural" inclinación de los varones a la variabilidad, las nuevas emociones y la poligamia, el divorcio permite devolver la libertad perdida a ambos, dentro de un marco legal que promueve la honra y evita alternativas inmorales como el "amor 
libre". Con el adulterio masculino (y sin ley de divorcio), se produciría una serie de deshonras para la mujer: la hipocresía al ocultarlo o la alternativa de abandonar el hogar, trabajando en cualquier oficio por un salario indigno y recibiendo una pensión miserable. Frente a la pobreza y la desprotección, un camino frecuente para muchas será transformarse en amantes o "queridas", eufemismo de la prostitución. De ahí, casi inevitables serán los embarazos no deseados y sus consecuentes "infanticidios prenatales" o abortos. Algo remedia la ley que devuelve a la mujer su patrimonio o herencia. Pero aquellas que no cuentan con dinero propio, más allá de la clase social, deberán enfrentarse por igual a la búsqueda de un empleo sin profesión y con mínimos conocimientos para desempeñar cualquier oficio. La educación de las mujeres también podría contribuir a su autonomía, pero los estudios están subordinados a la prioridad de ser madre, interrumpiendo por ello muchas veces una carrera y restringiendo las posibilidades laborales futuras. La religión ha permitido por siglos y de forma hipócrita la anulación, y el divorcio en muchos países del mundo ya está legislado y no por ello se rompen más matrimonios que en los lugares donde no es legal. Si se piensa en los hijos, es fácil imaginarlos mejor en ambientes libres de violencia, de modo que también pareciera ser una buena razón para salvaguardar la seguridad y protección de los niños.

Margarita y Gastón, los dos personajes amarrados aún a sus cónyuges, miran con indignación la legislación chilena, afirmando que "la justicia es un mito", "un negocio como cualquier otro" (Rouge, Los fracasados 95). Mientras el país ha puesto sus ojos en el "roto" y la "cuestión social" y los socialistas creen "que con la expropiación de las tierras y la abolición del capital se soluciona el problema de la felicidad humana" (Rouge, Los fracasados 115), descuidan la cuestión moral de la familia. “Cómo es posible que todavía hayan personas que piensen que es moral que no exista la ley de divorcio?", se pregunta Gastón. "¿Cuántos hombres como yo se ven condenados por un engaño a un eterno suplicio?", incluyendo con esto a los varones entre los afectados por la ausencia de la ley.

¡Yo romperé este lazo! Esto no puede continuar por más tiempo. Dedicaré el resto que me queda de vida a luchar porque se dicte esta ley que hace falta cimentar la dicha de muchos. ¡Lucharé encarnizadamente! Pronto repartiré por todo el país los folletos que ya están en prensa, folletos que son gritos de protesta contra nuestra ley. Haré la propaganda de libros que comprueben que es necesario para el bienestar social, dictar el divorcio. ¡Convertiré mi vida en un apostolado!" (Rouge, Los fracasados 233). 
Delie Rouge, en efecto, fue, como ya mencionábamos más arriba, una de las primeras autoras en plantear abiertamente la necesidad de una ley de divorcio. Ya en Mis observaciones (1915) criticaba "la ley de 'divorcio' vigente en su país, por conceder al hombre la libertad de hecho mientras dejaba a la mujer en estado de bancarrota moral" (Lavrín 308), cuando todavía "el feminismo de clase media y alta se encontraba en etapa de formación y aún no había madurado del todo en cuanto a fuerza intelectual y social" (ibid.). Con su novela, Delie Rouge se anticipaba dos años a una discusión que recién en 1924 se abre al debate parlamentario que, como sabemos, vendría a resolverse ochenta años después, con la aprobación de la ley en 2004.

El espíritu constitucionalista de inicios de siglo, que decanta en una nueva legislación el año 1925, no veía otra forma de resolver los problemas sociales sino a partir de cambios en la jurisprudencia: el divorcio, el aborto, el sufragio, las leyes laborales, las reformas educacionales y de la propiedad son temas que comienzan a debatirse muy tempranamente y su discusión se extiende durante toda la primera mitad del siglo. Ya para la década del sesenta el tono había cambiado $\mathrm{y}$, aunque aún quedaban muchas de estas materias en el tintero, la expectativa de abordarlas legalmente había pasado a un segundo plano. Tal vez contribuyó a esta decepción legalista el hecho de que la ansiada obtención del voto en 1949 no democratizara ni cambiara mayormente las vidas de las mujeres. "Mi mamá no se da cuenta de que ya pronto voy a tener derecho a voto. Me reta el día entero. Mi papá igual” (112), dice Marta, la protagonista de La culpa (1963) de Margarita Aguirre. En un tono aparentemente liviano y despreocupado, Marta enfatiza la condición de niñas con que siguen siendo consideradas las mujeres, sumado esto a una educación que les enrostra su inutilidad en este constante decirse "no sirvo para nada" (Aguirre 261).

Estamos a inicios de la década de los sesenta y el pálpito de los tiempos o el retrato de lo contemporáneo domina la nota que le quiere dar Valdivieso a su relato con la historia de esta mujer que podría ser cualquiera de "nuestra generación” (La brecha 8). No es muy distinto al propósito de Delie Rouge con Los fracasados, imagen fresca, una instantánea de su época. Pero entre los casi cuarenta años que distan entre estos dos textos, se ha dejado atrás la mitificación del matrimonio, de la maternidad y la confianza en la legislación como remedio a los problemas. El ideal del matrimonio como realización y expresión de la felicidad humana parece ponerse en tela de juicio, y la literatura de mediados de siglo será una expresión de ello. Por solo dar un ejemplo, tal vez extremo, pensemos en Cárcel de mujeres (1956) de María 
Carolina Geel. La protagonista ha asesinado a su expareja e indaga en las motivaciones que le llevaron a cometer el crimen. Entre algunas de las razones que sopesa, descubre su horrorizada reacción frente a la marcha nupcial que se escuchaba en la radio el día que el hombre le propone iniciar una vida en común. Resuelve en ese instante que "esas nupcias no se consumarían" y luego lo explica señalando que "todo el bien que él pudiera darme no alcanzaría a desplazar la espantosa miseria moral que el matrimonio llega a infiltrar en los seres" (Geel 77). Acá ya no se busca proteger moralmente a la mujer con un nuevo matrimonio, sino, por el contrario, escapar de esa "miseria moral" que tiñe todo al estar casados, hasta "infiltrarse" en los seres. Con mayor ligereza, pero igual escepticismo, la protagonista de La brecha enfrenta el fetichismo de los rituales del casamiento. Un "inexplicable pudor" le impide "dedicarle mucha atención" a la única fotografía de su boda, escondida entre las páginas de un libro. El mismo efecto le produce la copia enmarcada que posa sobre la chimenea de la casa de la suegra, confiesa, girándola discretamente hacia la pared cada vez que puede. En este caso, sin violencia, sin dramatismo va soltando las "amarras inútiles", "abriendo la brecha" que la empuja a salir de la casa, con o sin nulidad. Un día, su marido dará a entender su deseo por iniciar otra relación. "Fue el principio; lo demás llegó poco a poco. Presenté la nulidad y no tuve rechazo" (Valdivieso, La brecha 131).

La protagonista se sabe privilegiada y con esa confianza obtiene la nulidad, un contacto para hacerse un aborto y otro para obtener un empleo. Con o sin nulidad, con o sin ley de divorcio, sabe que puede romper las amarras matrimoniales. De ahí su distancia frente a la discusión legal:

Un matrimonio que se disuelve da el ejemplo: mientras algunos se alegran, otros, los que tiemblan por su insegura tranquilidad constituida, anatematizan contra los rebeldes. Recordé a un amigo del teatro que aseguraba que primero aprueban en el Congreso la ley de reforma agraria que la ley de divorcio. El bolsillo o el alma. ¿Qué ley saldrá primero? (Valdivieso, La brecha 87 ).

Como Delie Rouge, ve que en el Congreso la ley de divorcio aún compite con la de reforma agraria. Pero el problema ha dejado de ser un asunto moral para volverse más bien una prioridad del "alma". Tal vez fuese la entonación del alma lo que la protagonista imagina en caso de "escribir un libro; sería como una catarsis, no contar nada: gritar, dejar los tonos menores, tono mayor sostenido" (Valdivieso, La brecha 102). 


\section{“GANARÁS EL PAN CON EL SUDOR DE TU FRENTE"}

La protagonista de La brecha piensa como una maldición de Dios la entrada de las mujeres al mundo del trabajo. Ahora, además de "parir los hijos con dolor" - la obligación patriarcal de la función reproductiva capitalista, en términos de Federici-, las mujeres deberán "ganarse el pan con el sudor de tu frente". Doble función, doble explotación: "Ambas maldiciones me tocan" (Valdivieso, La brecha 113), dice con resignación.

Las mujeres de comienzos de siglo parecían tener claridad respecto a la doble explotación que implicaba asumir las ya tradicionales labores domésticas y el ejercicio de la profesión fuera del hogar, lo que Silvia Federici, en El patriarcado del salario (2018), distingue como el trabajo de reproducción (de procreación, sexualidad y formación de la mano de obra) y el trabajo asalariado de la producción de mercancías y bienes. La sobrina de Gastón, en Los fracasados (1922), que estudia medicina con mucha pasión, le advierte que "cuando me case, tiíto, no ejerceré mi profesión. Sólo seré madre y no Doctora. ¡No se puede servir a dos señores! Bastante tendré yo con la educación moral de mis hijos y con hacer bello y agradable mi hogar" (109). Esta temprana conciencia de no poder servir al marido y al patrón simultáneamente tiene algo de la rebeldía feminista que Federici se encarga de describir a propósito de la iniciativa del Comité del Salario para el Trabajo Doméstico (WfH, por sus siglas en inglés): "En lo tocante a nosotras, no nos ofrecen solo el "derecho a trabajar" (esto se lo ofrecen a todos los trabajadores) sino que nos ofrecen el derecho a trabajar más, el derecho a estar más explotadas" (28).

En términos similares pensará la protagonista de La brecha la división sexual del trabajo, como "dos maldiciones laborales", naturalizadas bajo el discurso del designio divino. Una lejana utopía precapitalista la hace remontarse "a miles de años atrás", cuando la "tierra germinaba trigo y manaba agua, el hombre se satisfacía de ella espontáneamente y no moría de hambre; allí estaba la inmensa superficie generosa tendida al sol como un banquete. No existían oficinas todavía" (Valdivieso, La brecha 129-130). El regreso al mito del paraíso perdido permite, paradójicamente, desnaturalizar la condición aparentemente biológica de la división sexual del trabajo, imaginando una relación con la naturaleza y el medio ambiente distinta a la del sistema productivo capitalista, sin clases y sin géneros. La estructura capitalista, o la que llama "médula espinal de nuestra sociedad" (Valdivieso, La brecha 134), en cambio, generaría la explotación a través del salario, 
traducido en el miedo que observa "en el rostro de mis compañeros", que "temblaban pensando que podría cerrarse la puerta de sus empleos y quedar a la intemperie" (ibid.). La obtención de un sueldo le permite ingresar también -tal como sus compañeros varones- a la cadena de producción reconocida -según la tesis de Federici-, a la visibilización y legitimación de su trabajo por medio de la paga y, convengámoslo, le abre el camino hacia la autonomía. Con dinero podía financiar sus gastos y podía, sobre todo, cortar los lazos de dependencia con su marido: "El dinero ganado me alejaba; segura económicamente, ¿cómo podría cogerme? Ya no estaría en vigencia aquello del respeto debido a quien lleva y mantiene los gastos, su última arma descargada contra mí" (Valdivieso, La brecha 123). El trabajo asalariado es para esta mujer una obligación que nada tiene que ver con la realización personal. Es una orden recibida "desde arriba", eliminando "así toda posibilidad de elección verdadera" (Valdivieso, La brecha 132).

En la descripción detallada que la protagonista hace de su primer día de trabajo se respira también la conciencia de pertenecer a la primera generación de mujeres que ha vivido estos cambios. Y es que, en efecto, son pocas las escenas de trabajo asalariado protagonizadas por mujeres en nuestra literatura, más allá por cierto de la tan latamente abordada prostitución, materia predilecta de los escritores desde el siglo XIX en adelante. Los oficios que aborda el criollismo de Marta Brunet son el retrato fidedigno de los esfuerzos de las mujeres pobres por aportar adicionalmente a la economía del hogar, realizando labores asociadas al género, como las manualidades, la costura, el tejido -aquí pensamos en la protagonista de "Soledad de la sangre" (1943)-, o la cocina -como doña Clara y su hija Cata en Montaña adentro (1923)-. Oficios feminizados y remunerados como secretariado, telefonista o maestra son también materia de las narrativas de Brunet, en María Nadie (1957), de María Flora Yáñez, en Espejo sin imagen (1936) -con la comprometida educadora que enseña a los párvulos de la hacienda-, de Ester Matte en su cuento "El caso" (1965) -que denuncia la precariedad laboral y la discrecionalidad salarial de la que son víctimas las secretarias- o de Maite Allamand en Huellas en la ciudad (1966), quien de la esclavitud del secretariado pasa a liberarse del empleador montando un taller de costura en su casa. Todas ellas comparten la condición de solteras, percibidas por el resto con cierta anomalía, y tantean con ambivalencia las ventajas y desventajas del matrimonio. A este grupo podríamos incorporar a la obrera de "Juana y la cibernética" de María Elena Aldunate, un texto de 1963 que retrata una vida parecida a la de estas mujeres: la de una 
trabajadora sin tiempo para el amor y sin ayuda masculina, que enfrenta sola la mantención de su madre.

María Flora Yáñez fue una escritora que le dio un espacio central a la hacienda en su narrativa, para relatar los pormenores económicos que, en general, no habían sido materia de la literatura, más preocupada en describir romances, costumbres, ocios o las típicas diferencias de clase entre campesinos y patrones. A Yáñez, en cambio, le interesa el funcionamiento económico y técnico del trabajo de la tierra. Le preocupa la ausencia del patrón en la administración del campo y anticipa las calamidades que esta falta de liderazgo genera en la estructura social del latifundio, principalmente entre los trabajadores. En Espejo sin imagen, la debilidad del patrón desencadena catástrofes que afectan el bienestar del campo, pero también la felicidad de los mandos medios y del campesinado, que conducen al suicido del administrador, al despido de la maestra rural, y a crímenes y violaciones entre los trabajadores. Desde la perspectiva de sus dueños, esta vez, en ¿Dónde está el trigo y el vino? (1962), la ausencia de jefe y, sobre todo, de la figura de un patriarca será la gran preocupación de la familia de herederos. Y, como buena parte de la narrativa de la época, no están ausentes las críticas a la ociosidad de esta aristocracia cada vez más venida a menos. Olivia, una de las voces protagónicas de la historia, resulta ser la única interesada en el valor de la tierra y en el firme deseo de no venderla, si bien la amenaza de la expropiación y la aprobación de la ley de reforma agraria es cada vez más inminente. Una situación similar relata Mercedes Valdivieso en La tierra que les di (1963), su segunda novela. El esfuerzo de una generación que adquirió las tierras se despilfarra en las manos de sus herederos. Lo interesante de todos estos relatos es que centra la preocupación por la propiedad en personajes femeninos -en contra de la tendencia familiar-, e incluso asigna a la mujer su final administración, como es el caso de la novela Páramo salvaje (1963) de María Elena Gertner: una larga historia de abusos patronales -como el "derecho a pernada", los incestos familiares, los despidos de sirvientas embarazadas y las violaciones a niñas-, que acusan la violencia sexual que domina el micromundo de la hacienda y que, para estas novelistas, es expresión de la tiranía patriarcal en el Chile del agro. Esta larga historia concluye, en Páramo salvaje, con el gobierno de Catalina, quien repara las injusticias cometidas por su amante y hermanastro, el hasta entonces patrón de la hacienda. Las mismas violencias sexuales, la misma desidia frente a la producción agrícola para, en su lugar, optar por el contrabando como forma de negocio, se repiten y constituyen el sello que 
este hombre imprime a su gestión. Catalina, una vez muerto el hermano, restituye la justicia en la hacienda con el acercamiento a los trabajadores y con el firme propósito de germinar otra vez la tierra.

No es casualidad que estas tres novelas -las de Yáñez, Valdivieso y Gertner- se hayan publicado entre 1962 y 1963, cuando comienza a hacerse efectiva la primera ley de reforma agraria y se discutía la expropiación del latifundio para darle "la tierra al que la trabaja". Puestas en la balanza la ley de divorcio y la de reforma agraria, tal como Delie Rouge y Mercedes Valdivieso lo plantean, parecía avanzarse agigantadamente en otorgarles derechos a los trabajadores y al campesinado, mientras la justicia hacia las mujeres dormía en el Congreso con postergados proyectos de ley. En este "castigo" (o ajusticiamiento) a los patrones por sus abusos contra mujeres, niños y campesinos, sus mujeres, las herederas, salían perdiendo más que ellos: sin patrimonio, sin educación, sin profesión, sin ley de divorcio, sin posibilidades, en definitiva, de ganarse la vida.

Para la narrativa de los cincuenta, como se ve, el asunto del trabajo femenino será una preocupación central que no está, por cierto, desconectada de los procesos sociales que modificaron la vida de muchas mujeres de la época. Estas autoras provenían, en su mayoría, de familias acomodadas, pero la crisis del 29, la revuelta social y la transformación social del latifundio dejaron en muy mal pie la economía de muchos hogares y varias de ellas debieron salir a ganarse la vida. Las deficiencias de la educación no contribuían a potenciar sus capacidades ni su seguridad profesional, de modo que los relatos de vida de estas mujeres de medio siglo son en buena parte las luchas que debieron dar por hacerse un espacio en la escena pública. A autoras como Valdivieso, Gertner o Yáñez debemos sumar los nombres de Margarita Aguirre y Elisa Serrana. Novelas como La derrota (1964) de Gertner - que es, en buenas cuentas, la aceptación de la derrota de tener que trabajar-, La culpa (1964) de Margarita Aguirre -que aborda la titánica empresa de la autonomía económica cuando ni educación, ni profesión sino que solo culpas se reciben de herencia-, o Chilena, casada, sin profesión (1963) de Elisa Serrana, son algunas de las obras publicadas después de La brecha que también articulan la caída del antiguo mundo y la fisura que se les abre a las mujeres al tener que "ganarse el pan".

Como estas mujeres, la protagonista de La brecha hace visible, en su propia trayectoria hacia la autonomía, un recorrido que va de las búsquedas informales por el sustento económico a una cierta adaptación social, que significa aceptar su nueva condición de trabajadora, "esclava" o "reclusa", 
para decirlo en sus términos. La autonomía no está libre de negociaciones. Y lo que nos enseña esta mujer es que la libertad cuesta mucho conquistarla.

Pongo más leños al fuego y pienso que soy como un recluso que hizo saltar la cerradura de su calabozo y a quien, después de ciertas escaramuzas, le está permitido pasearse por la enorme cárcel, conversar con los presos en sus celdas y luego sentarse a esperar frente a la puerta. Porque es allí fuera donde está la libertad... (Valdivieso, $L a$ brecha 142).

\section{ALGUNAS CONSIDERACIONES FINALES}

La brecha articula una voz femenina lúcida y alejada de todo dramatismo, que relata su vida en un tono marcado por la autoconsciencia. Sin afectaciones ni victimizaciones, la protagonista narra sucesos difíciles y penosos de su recorrido vital, pasando por un matrimonio que transita desde desavenencias menores hasta una relación hostil y violenta, un embarazo experimentado como malestar y encierro, un aborto representado como doloroso pero necesario y la necesidad de encontrar un trabajo y sustentarse económicamente. Las frases breves y el lenguaje llano, casi lacónico, son rasgos distintivos del texto de Mercedes Valdivieso y forman parte de las razones que le otorgan el lugar de ser una de las novelas feministas más visibles dentro de la tradición literaria de Chile y Latinoamérica.

El recorrido que hemos querido trazar ha considerado una serie de obras narrativas escritas tanto antes como contemporáneamente a La brecha, para ir marcando diferencias y semejanzas en el tratamiento de los temas que destacamos como centrales dentro de la novela: el aborto, el divorcio y el trabajo. Las políticas del cuerpo que se ven implicadas en estas temáticas son las que han sido decisivas en la subordinación de la mujer y, siguiendo a Federici, hemos mostrado la imbricación de problemáticas de género y de clase: es en este núcleo entre reproducción y producción, y las formas en que se organizan ambas en el sistema patriarcal, donde se cifra la pregunta por la emancipación feminista. La brecha, leída desde estas coordenadas, revela su potencial subversivo, pues la paulatina conquista de autonomía de su protagonista pasa, precisamente, por la liberación de los amarres que permitían su dominación. Debe hacerse dueña de su cuerpo, para lo cual la decisión de abortar es fundamental, marcando una toma de posesión con 
relación a su corporalidad; debe matar al padre, en un sentido figurado, para poder sustituir su ley por otra, inaugurada por ella misma; y debe entrar en la lógica de la producción, para generar las condiciones materiales que le permitan su emancipación. Y si bien ha pasado medio siglo desde su publicación, esta novela de Mercedes Valdivieso aún evidencia, en muchos sentidos, una actualidad sorprendente. Las marchas feministas de los últimos años así lo demuestran, destacando las resistencias del patriarcado frente a la igualdad de género e insistiendo en las marcas de género que siguen inscribiéndose en los cuerpos y las vidas de las mujeres. Volver a leer y a poner en perspectiva La brecha se transforma así en un gesto necesario para seguir achicando en pos de eliminar la brecha que separa a hombres de mujeres.

\section{BIBLIOGRAFÍA}

Aguirre, Margarita. La culpa. Santiago, Editorial Zig-Zag, 1963.

Aldunate, Elena. Juana y la cibernética. Santiago, Arancibia Hermanos, 1963.

Allamand, Maite. Huellas en la ciudad. Santiago, Editorial Pacífico, 1966.

Brunet, Marta. María Nadie. Santiago de Chile, Editorial Universitaria, 2009. Montaña adentro. Santiago, Nascimento, 1923. Aguas abajo. Santiago, Editorial Cruz del Sur, 1943.

Caddou, Marcelo. "Relectura de La brecha de Mercedes Valdivieso". Inti: Revista de literatura hispánica 1, №29, 1989, pp. 29-30, 39-48.

CÁnovas, Rodrigo. Sexualidad y cultura en la novela hispanoamericana. La alegoría del prostíbulo. Santiago, LOM, 2003.

Darrigrandi, Claudia. “Trayecto urbano, aprendizaje y decepción: Juana Lucero se (re)descubre en el Santiago de fin de siglo (XIX-XX)". Nuevo Mundo. Mundos nuevos (web), 31 de mayo de 2009, consultado el 21 de noviembre de 2021, disponible en: https:// journals.openedition.org/nuevomundo/56205

D’Halmar, Augusto. Juana Lucero. Los vicios de Chile. Santiago, Imprenta, litografía y encuadernación Turín, 1902.

Federici, Silvia. Calibán y la bruja. Mujeres, cuerpo y acumulación originaria. Buenos Aires, Tinta Limón, 2010.

El patriarcado del salario. Críticas feministas al marxismo. Madrid, Traficantes de sueños, 2018.

Geel, María Carolina. Cárcel de mujeres. Santiago, Editorial Zig-Zag, 1956.

Gertner, María Elena. La derrota. Santiago, Editorial Zig-Zag, 1965. 
Páramo salvaje. Santiago, Editorial Zig-Zag, 1963.

Lavrín, Asunción. Mujeres, feminismo y cambio social en Argentina, Chile y Uruguay 1890-1940. Santiago, Centro de Investigación Diego Barros Arana, 2005.

Matte, Ester. "Un caso”. El cuento femenino chileno. Manuel Balbontín y Javier Rodríguez (eds.), Santiago, Ediciones Orbe, 1965.

Olea, Raquel. "Escritoras de la generación del cincuenta. Claves para una lectura política". Revista Universum 2, N²5, 2010, pp. 101-116.

Rouge, Delie. Los fracasados. Santiago de Chile, Imprenta New York, 1922. Mis observaciones. Santiago, Imprenta New York, 1915.

Serrana, Elisa. Chilena, casada, sin profesión. Santiago, Editorial Zig-Zag, 1963.

Valdivieso, Mercedes. La brecha. Santiago, Editorial Zig-Zag, 1961. La tierra que les di. Santiago, Editorial Zig-Zag, 1963.

YÁÑEz, María Flora. Espejo sin imagen. Santiago, Nascimento, 1936. ¿Dónde está el trigo y el vino? Santiago, Editorial Zig-Zag, 1962. 